\title{
Evidence for generalized quantifier semantics in the interpretation of the English neuter singular pronoun
}

\section{Paul Elbourne ${ }^{1}$}

Accepted: 18 June 2021 / Published online: 13 July 2021

(c) The Author(s) 2021

\begin{abstract}
The English pronoun it can anaphorically take on the meaning of a salient generalized quantifier when it occurs in subject position followed by an elided Verb Phrase and (optionally) a VP-level operator. The extent to which theories of pronoun interpretation will have to be altered to take account of this finding will depend on whether the phenomenon is unique to English or part of a crosslinguistic pattern.
\end{abstract}

Keywords Pronouns · Generalized quantifiers · Anaphora · Ellipsis · Pronominalization $\cdot$ Tag questions $\cdot$ Negative indefinites

\section{Introduction}

My chief purpose in this paper is to make an empirical claim: the English pronoun it, in restricted circumstances, can have the semantics of a generalized quantifier. To be more precise, it can have the semantics of a contextually salient generalized quantifier, having seemingly picked up this meaning by means of some anaphoric process. ${ }^{1}$ Of course Montague (1973) claimed that all DPs, including pronouns, had the semantics of generalized quantifiers; but that was part of his strategy of maintaining consistency in the allocation of types to syntactic categories by 'generalizing to the worst case' (Partee 1996); his pronoun denotations could be arrived at by raising individual variables to the type of generalized quantifiers by means of a type-shifting rule of the kind explored in Partee 1986. That is not the kind of thing that I mean when I claim, in the present paper, that it can have the semantics of a generalized quantifier. Then again, Cooper (1979), Davies (1981), and Neale (1990) analysed various instances of donkey anaphora and related phenomena as involving pronouns

\footnotetext{
${ }^{1}$ In this article I will understand anaphora and related words in a very general sense, just having to do with the interpretation of a linguistic item being dependent on that of some other linguistic item. I do not mean by these terms to suggest any particular analysis of this phenomenon.
}

$\triangle$ P. Elbourne

paul.elbourne@magd.ox.ac.uk

1 Magdalen College, Oxford OX1 4AU, UK 
interpreted as definite descriptions; and they analysed definite descriptions in a neoRussellian way, as generalized quantifiers. This is not the kind of thing I mean either. I mean that it can have a wide range of generalized quantifier meanings, a range that goes far beyond Russellian definite descriptions and type-shifted individual variables to encompass things like 'something' and 'every towel'.

As far as I know, this is a novel claim. ${ }^{2}$ There is no consensus on the interpretation of pronouns, but past and current work has generally argued for one of three positions: that pronouns are individual variables, that they are covert definite descriptions, or that they are identity functions. The theory that pronouns are individual variables is perhaps the most natural: given the apparent bound and referential uses of pronouns, the temptation to assimilate them to individual variables in first-order logic is great. The basic idea goes back to Frege (1903, pp. 79-80), and was developed in more detail by Quine (1960) and Geach (1962, pp. 108-112). Donkey anaphora and related phenomena seemed for a while to present a serious difficulty for the theory, but the work of Heim (1982) and Kamp (1981) showed that it could in fact handle at least some of those data; and many recent theories are based on the pioneering work of Kamp and Heim (most prominently perhaps Groenendijk and Stokhof 1990, 1991 and van Eijck and Kamp 1997).

The theory that pronouns are covert definite descriptions originates in analyses of donkey anaphora by Cooper (1979) and Davies (1981). (Evans (1977, 1980) had produced a superficially similar but actually very different theory according to which donkey pronouns were in fact referential and had their references fixed by definite descriptions extracted from the linguistic environment.) Other prominent advocates of a description-based approach to donkey anaphora and similar phenomena are Heim (1990) and Neale (1990). Given that languages do not seem to make any formal distinction between donkey pronouns, on the one hand, and referential and bound ones, on the other, it is unsatisfying to suppose that pronouns are definite descriptions sometimes and individual variables the rest of the time; so it was suggested by Elbourne (2005) and Neale (2006) that referential and bound pronouns also be treated as definite descriptions, perhaps trivial ones like 'the entity identical to John' or 'the entity identical to $x$ '. Meanwhile, apart from donkey anaphora and similar phenomena, there are at least two other ways to argue that pronouns are semantically definite descriptions: by means of the descriptive indexical readings pointed out by Nunberg (1993) (see Elbourne 2008, 2013); and by means of Voldemort phrases like he who laughs last, which seems to mean something like 'the person who laughs last', which in turn arguably implies a meaning like that of the definite article for he (Elbourne 2005, 2013). (See (20), below, for further examples of this construction.)

Another, and perhaps more radical, way of departing from the conclusion that pronouns have the semantics of individual variables is that associated with the tradition of variable-free semantics. Variable-free semantics was first suggested as a possibility for natural language by Quine (1960) and Szabolcsi (1989). The basic idea is that nothing in natural language has the semantics of a variable; semantic systems are based, instead, on the combinators used in combinatory logic (Curry and Feys 1958). This naturally excludes the possibility of assimilating pronouns to individual variables. Analyses of referential, bound, and donkey-anaphoric uses of pronouns have

${ }^{2}$ I gave a brief preview of the relevant data in Elbourne (2011, pp. 119f.) 
been produced in this kind of system by Jacobson (1999, 2000), who argues that pronouns denote the identity function over individuals. Closely related work is to be found in Barker and Shan 2008 and related publications.

The important point to note for present purposes is that none of the theories described in the last three paragraphs claims that pronouns can have the semantics of generalized quantifiers (with the partial and limited exception of the Russellian definite descriptions posited as pronoun meanings by Neale 1990), and none of the work in these traditions, as far as I know, has analysed data like the ones that follow. The theoretical conception that would most easily allow for these data is perhaps Geach's (1962, pp. 151f.) notion of a pronoun of laziness, which is a pronoun that is equivalent to an exact repetition of its antecedent. The pronoun tokens to be examined in this article are certainly pronouns of laziness, although Geach does not give any examples like the ones to follow.

Since questions of analysis will immediately present themselves to theoretically sophisticated readers, I will interweave data and analysis in what follows. I will begin with one illustrative example and work from there. It should be acknowledged before we begin that I do not have deep explanations for all aspects of these novel data. I hope that other theorists might be inspired to work on them and improve on what I have here.

\section{Universal quantification}

One day, some years ago now, I found myself in the following discussion with someone near and dear to me:

SP: Every towel has a purpose.

PE: No, it doesn't!

The details of our dispute are now sunk in merciful oblivion. But it is worth dwelling for a while over the occurrence of the pronoun it. From the above transcript, it looks as if I might possibly have been referring to one towel in particular (perhaps with the aid of a gesture) and saying of it, as we say, that it did not have a purpose. The pronoun, in other words, might be thought to be referential, if all we had to go on was the above transcript. But this is not what I was doing. I did not have the intention to refer to a particular towel. No gestures accompanied my utterance. And, in terms of intonation, the pronoun was downstressed and did not have the contrastive stress that would be necessary in such circumstances to use the pronoun referentially. (And such a stressed, referential use of $i t$ is not very good in my dialect anyway.)

My meaning, if we can trust my intuitions on this point, was 'It is not the case that every towel has a purpose.' Note the scope of the universal quantifier and negation. My intention was not to claim that all towels lack a purpose. I was quite content to admit that the dish-cloth hanging up near the kitchen sink had a perfectly well-defined purpose in life, viz. the drying of dishes. But, for reasons which are now obscure to me, I was keen to deny that all the towels over which I was quantifying were fitted with purposes. My own analysis of this utterance is simple and easily yields up this meaning: it means 'every towel', having assumed this meaning by means of 
an anaphoric process on the basis of the occurrence of every towel in the previous sentence; and for purposes of interpretation it scopes below negation, as universal quantifiers in subject position often do.

Other analytic possibilities might suggest themselves, but before we explore them I would like to add to our database, in order to assure the reader that I am not the only person ever to have come out with such a bizarre utterance. The following naturally occurring examples were found by means of a corpus search:

(2) (Part of a questionnaire...) What women get wrong about men: 'That everything we say has some hidden meaning. It doesn't.'

(Cosmopolitan, Vol. 247, Issue 5, p. 136, November 2009)

(Then-Senator Obama is talking about how nice people are to him now that he is a senator.) And they pretend that everything that you say makes sense, which it doesn't, right?

(The Oprah Winfrey Show, 2005-01-19)

The meaning of the last sentence of (2) is evidently 'It is not the case that everything we say has some hidden meaning'. As for (3), Obama is here modestly admitting that it is not the case that everything he says makes sense; but we can hardly expect the future president to be so self-deprecating as to assert that nothing he says makes sense, which would be the upshot of the alternative scopal construal. (I emphasize the scopal possibilities because this issue is relevant to an alternative analysis of these data that we will examine in a moment.) Nor, I suspect, is he referring by means of the pronoun to everything he says, considered en masse, and saying that it as a whole does not make sense.

There is an alternative analysis that might be adduced, which would avoid the conclusion that it has generalized quantifier meanings in these examples. ${ }^{3}$ Much of the rest of this article will be devoted to refuting this analysis, and various offshoots and descendants of it, in different ways. The analysis I am thinking of says that the apparent universal quantification here is due to telescoping.

Telescoping is when a universal quantifier in one sentence appears to bind a pronoun in the following sentence (Roberts 1989). An example, due to Barbara Partee (personal communication to Craige Roberts), is the following (Roberts 1989, p. 717):

(4) Each degree candidate walked to the stage. He took his diploma from the Dean and returned to his seat.

\footnotetext{
${ }^{3}$ Here are two other initially tempting thoughts that turn out to be non-starters. First, one might be tempted to see the pronoun as referring to an individual sum in Link's (1983) sense; one could then see the apparent universal quantification as arising from distributivity. (It is notable that all the predicates in the examples we have seen so far are distributive.) But in the kind of mereological semantics that is involved here, only plurals (and conjunctions) can refer to complex i-sums. Secondly, one might also be tempted to see the pronoun as a stand-in for a generic definite description, of the type seen in The lion has four legs; but the sentences in question do not seem to be generics; and it is not clear that a pronoun can stand in for a generic definite description without an antecedent that is a generic definite description. These two analyses also fall down because they seem to be restricted to universal (or generic) quantificational force; it is not at all clear how they could handle the different quantificational forces to be introduced in Section 3.
} 
This can easily be understood as claiming that each degree candidate walked to the stage, took his diploma from the Dean, and returned to his seat. It is as if the initial universal quantifier can bind into the second sentence, then; and indeed analyses along exactly these lines have been proposed, with widely varying technical implementations, by Groenendijk and Stokhof (1990) and Keshet (2008). The important point to note for current purposes is that, as one would expect if the quantifier phrase in the first sentence could bind into the second, in all the standard telescoping data the universal quantifier takes scope over all elements of the second sentence. Here is a representative selection of examples:

(5) a. Each student ${ }_{i}$ in the syntax class was accused of cheating on the exam and he $\mathrm{e}_{i}$ was reprimanded by the Dean.

(Fodor and Sag 1982)

b. Each candidate E $_{i}$ for the space mission meets all our requirements. $\mathrm{He}_{i}$ has a $\mathrm{PhD}$ in astrophysics and extensive prior flight experience.

(Roberts 1987)

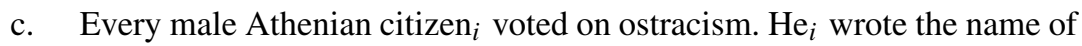
the candidate on a piece of pottery.

(Geoffrey Nunberg, cited by Poesio and Zucchi (1992))

d. Every story ${ }_{i}$ pleases these children. If $i_{i}$ is about animals, they are excited, if it $_{i}$ is about witches, they are enchanted, and if $\mathrm{it}_{i}$ is about humans, they never want me to stop.

(Belvadi 1989)

In examples $(5 \mathrm{a}-\mathrm{c})$, the pronoun apparently bound (he in each case) stands at the start of the sentence, forcing the binder, whatever it is, to have scope over the entire sentence; and in the case of $(5 \mathrm{~d})$ we can tell that the binder must have scope over if, since the meaning is 'Every story is such that if it is about animals...'; it is not 'If every story is about animals...'. ${ }^{4}$ But this is not the case with examples (1)-(3): in these cases, the paraphrase of the sentence in question has the universal quantifier take scope below sentential negation. In this respect, then, it is hard to assimilate example (1) to telescoping.

To be precise, the scopal relation in (1) makes it impossible to assimilate this example to telescoping if telescoping is to be analysed along the lines already mentioned, as involving the quantifier phrase from the introductory sentence taking scope over the second sentence. Then, indeed, we would expect only wide scope for the universal quantifier. But there is another tradition within the analysis of telescoping that maintains that the quantifier responsible for the interpretation of the pronoun is an entity separate from the quantifier phrase in the first sentence (Poesio and Zucchi 1992; von Fintel 1998; Anderssen 2011). Anderssen (2011, pp. 58-62), for example, takes the quantifier in question to be GEN, a quasi-universal quantifier over situations; and the pronouns in question are interpreted as definite descriptions incorporating bindable situation variables, as suggested for donkey anaphora by Heim (1990) and Elbourne (2005). Let us not be specific at this point, however, and allow, for the sake of argument, that there might be a phonologically null universal quantifier that

\footnotetext{
${ }^{4}$ This, of course, raises a problem for the view that pronouns can take on the meanings of contextually salient generalized quantifiers. Why can it not mean every story in this case? See Sect. 6 for a generalization that will cover this.
} 
can pick up restrictor material from the context and bind pronouns. If this is correct, it is surely open to us, we could argue, to maintain that the quantifier in question can scope below negation, even if this behaviour has not previously been observed. Thus we would be able to explain examples (1)-(3) without recourse to a new meaning for pronouns.

This is an attractive solution, at least insofar as anything involving telescoping can ever be attractive. But it runs into a few different problems. To elucidate some of them, we will need to look at some different categories of data, which we will do presently. But here is one that can be appreciated almost immediately. Such a solution seems to run into a serious problem with overgeneration. If there is a phonologically null universal quantifier that can pick up restrictor material from the linguistic context and bind pronouns, we would expect, for example, (6a) to have a reading equivalent to (6b), which is not the case. We can compare (6c), where anaphoric processes are perfectly well able to provide restrictor material for a bare quantifier (overt, in this case) and content for an elided VP. ${ }^{5}$

a. Talking about towels having purposes, it doesn't.

b. Talking about towels having purposes, every towel doesn't.

c. Talking about towels having purposes, some don't.

Of course this example might also be a problem for the analyses of telescoping presently under consideration, quite independently of the novel data adduced in the current article. But let us leave this now and go on to look at some more data.

\section{Other quantifiers}

If we expand our survey out beyond universal quantification, we will find some examples that bear striking resemblances to the ones we have examined so far but which involve different quantificational force.

Let us begin with pure existential force. Here is Nancy Blackett, one of the 'Amazons' in Arthur Ransome's Swallows and Amazons series of classic children's books, anticipating the arrival of her friends, the Swallows:

Oh well, they'll be here soon and something's sure to happen. It always does.

(Arthur Ransome, The Picts and the Martyrs, Chapter 24)

How should we analyse it in this utterance? It cannot be referential, since Nancy is evidently not referring to some particular event and saying that that always happens. Nor can it be a variable bound by something in some kind of cross-sentential binding, since the whole sequence does not mean '... there is some entity $x$ such that $x$ is sure to happen and $x$ always happens'. Nor is it possible, as far as I can see, to analyse the pronoun as a definite description here. Presumably, given the requirements for some kind of formal link to contextually available linguistic material that are imposed by

\footnotetext{
${ }^{5}$ An anonymous reviewer for this journal has suggested that the failure of the attempted anaphora in (6a) might be due to the mismatch between the singular pronoun and the plural antecedent towels. But things are not improved if we replace the introductory clause by Talking about a towel having a purpose....
} 
advocates of this kind of theory (Heim 1990; Elbourne 2001, 2005), such an analysis would have to have the pronoun meaning 'the thing' (on the basis of the occurrence of something); but the whole sequence does not mean '... something's sure to happen. The thing always does happen', whatever further efforts one makes to precisify or elaborate on this. The current theory, by contrast, can offer a natural analysis: the pronoun picks up the meaning of something. So the last sentence of the above passage means 'It is always the case that something happens', with, arguably, some kind of restrictor understood for always, perhaps something like 'when the Swallows arrive' or 'in the summer holidays'.

Staying with children's literature, in Chapter 13 of J.K. Rowling's Harry Potter and the Deathly Hallows, Harry is searching Dolores Umbridge's office at the Ministry of Magic for Slytherin's Locket, one of the Horcruxes into which Lord Voldemort has transferred part of his soul. Here is the crucial sentence, with a sentence on either side for context:

Then he turned to face the room again, raised his wand and murmured, 'Accio locket.' Nothing happened, but he had not expected it to; no doubt Umbridge knew all about protective charms and spells.

The meaning of the central sentence is, I submit, quite obvious. It can be paraphrased as in (9):

Nothing happened, but he had not expected anything to happen.

It is conceivable, I suppose, that it here could be a referential pronoun referring to the desired effect of the spell (that the locket be summoned). But that does not square with our intuitions about the sentence. And we can imagine a different context in which Harry waves his wand aimlessly around with no desired effect whatsoever; in this context the sentence is still fine and still intuitively seems to have the meaning in (9). So it, it appears, can take on the meaning of NPI anything by means of anaphora to nothing.

Given that there is anaphora to nothing, it is interesting that the pronoun in this example does not take on the meaning 'nothing'. In my judgement, the central sentence of (8) absolutely cannot mean '... he had not expected nothing to happen', whatever context I think of. I confirmed this intuition by means of an online survey of native speakers of English. ${ }^{6}$ The survey asked for synonymy judgements, which are admittedly something of a blunt instrument, but one adequate, I think, to produce a striking result in this case. The relevant survey questions were the following:

\footnotetext{
${ }^{6}$ The survey was conducted on SurveyMonkey; participants were unpaid and were recruited by means of a heavily subscribed Twitter feed. An introductory page explained what a native speaker of English was (there defined as someone who had learnt the language without formal instruction before the age of five) and asked that only native speakers participate. The target passages were the six to be found in examples (10)-(11), (14)-(15), (16)-(17), and (33)-(34); six fillers containing similar vocabulary were also included. For each question, subjects were asked to check a box next to 'Definitely', 'I think so', 'Not sure', 'I don't think so', or 'Definitely not'. In the event, I did not utilize the level of detail thus provided in the statistical analyses and pooled the 'Definitely' and 'I think so' responses to come up with a 'Yes' class, and pooled the 'I don't think so' and 'Definitely not' responses to come up with a 'No' class. Full experimental materials are available on request.
} 
(10) Consider the following passage:

Nothing happened, but he had not expected it to.

Can this mean 'Nothing happened, but he had not expected anything to happen'?

(11) Consider the following passage:

Nothing happened, but he had not expected it to.

Can this mean 'Nothing happened, but he had not expected nothing to happen'?

A total of 45 subjects answered both these questions: of these, 2 answered 'Not sure' to one or both of them and are not included in the current statistical analysis. Of the 43 remaining, 3 answered yes to both questions; 0 answered yes to (11) and no to (10); 36 answered no to (11) and yes to (10); and 4 answered no to both. Given the possibility of irrelevant biases towards saying yes to questions like this, the 3 who answered yes to both questions should not concern us too much; likewise those who answered no to both questions. The really crucial fact here is the contrast between the 36 who answered no to (11) and yes to (10), on the one hand, and the fact that no-one did the converse. This indicates a sharp difference in acceptability between the meaning in (10) (favoured) and the meaning in (11) (disfavoured). Applying McNemar's $\chi^{2}$ test with continuity correction, we see that the odds are vanishingly long that this contrast is due to chance (McNemar's $\chi^{2}=34.028$, df $\left.=1, p=5.433 \times 10^{-9}\right){ }^{7}$ I would argue that these facts lend support to the analysis of negative indefinites that sees them as syntactically complex items formed of a negation operator and an indefinite, spelled out as one item only in a post-syntactic process (Jacobs 1980; Rullmann 1995; Zeijlstra 2011): the presence of an indefinite in these structures explains why the current anaphoric process can pick up an existential meaning when applied to them. ${ }^{8}$

To return to our survey of quantifier meanings, we should note that it is not the case that these examples are confined to pure existential force, as the last two arguably were. Here, for a change of tone, is an extract from an academic article (Swoyer 2010, Suppl. 2, Sect. 2.1).

\footnotetext{
${ }^{7}$ For discussion of the use of McNemar's $\chi^{2}$ test in conducting simple linguistic experiments, see Myers 2009. All statistical analysis was carried out with the open-source package R, using the menemar.test () function.

${ }^{8}$ If we further suppose, with Jacobs (1980, p. 134), that the negation operator and the indefinite into which nothing decomposes do not form a constituent at the relevant syntactic level, so that no constituent in these examples has the meaning 'nothing', that would explain why hardly any of my informants gave responses consistent with the pronoun taking on that meaning here. However, an anonymous reviewer for this journal reports that he or she finds the following variant fine with the meaning 'just as Harry had expected nothing to happen':
}

(i) Nothing happened, just as Harry had expected it to.

This complicates things; so I will leave the full working out of the consequences for decompositional theories of negative indefinites for further research. It is perhaps worth remarking, however, that I personally find that (i) has a slightly paradoxical, 'Lewis Carroll' feel to it ('To be able to see nobody! And at that distance too!'), although I am not sure what to make of this. 
(12) In light of the vast literature on linguistic relativity hypotheses, one would expect that a good deal of careful experimental work had been done on the topic. It hasn't.

Here the final sentence means 'It is not the case that a good deal of careful experimental work has been done on the topic'. So it seems to mean 'a good deal of careful experimental work' and the quantificational force is 'a good deal of', not just pure existential force. One can easily make up variants with a great deal of, a small amount of, and so on, which work accordingly. In fact, one can show on the basis of (12) that there is an infinite number of quantificational forces that can figure in the construction under investigation, since one can make up variations with enough experimental work to take a whole day to read through, enough experimental work to take two whole days to read through, and so on. Following Meier (2003), I assume that to take... in these examples is construed with enough for purposes of interpretation and is presumably, therefore, its syntactic sister at the relevant level; I suspect it has been displaced to its surface position in each case by a process similar to Heavy NP Shift.

Overall, we are now in a position to dismiss the concern raised at the end of the last section to the effect that telescoping might be responsible for the novel data. Telescoping only trades in universal quantification (Roberts 1989, p. 717). There is no way that it can produce the phenomena discussed in the current section.

Even if we take the idea floated by Poesio and Zucchi (1992), von Fintel (1998), and Anderssen (2011), whereby a phonologically null quantifier is responsible for telescoping, and generalize it to include phonologically null quantifiers of other quantificational forces, we still do not arrive at an acceptable analysis: there would have to be a whole host of these phonologically null quantifiers hovering round, indeed very likely an infinite number, as we have seen; and it is much more economical to suppose that it can be a QP anaphor. Any analysis involving phonologically null quantifiers would also face the problem about overgeneration that we saw in (6).

There is perhaps one way left open to the sceptic. One could posit the existence, not of many separate phonologically null quantifiers of different quantificational forces, but of one phonologically null QP anaphor, which would pick up a quantifier-phrase meaning from a phrase of that type in the linguistic environment and bind pronouns with appropriate gender features, including it in these examples. This would have the advantage of positing only one phonologically null item instead of a whole host of them. It would also make the right prediction about (6a), since every towel is not present in the linguistic environment in that example. Could this be the way forward?

I do not think so. In describing this device, I have described exactly the behaviour that I am positing for it. Why would we posit a novel phonologically null item to be a QP anaphor when there is a phonologically overt item, a known anaphor, in all the right places, that could play the role instead? Such a solution starts to look extremely uneconomical.

The suspicious resemblance between this posited item and the pronoun it as I describe it will increase in the next section. 


\section{Other pronouns}

It is sometimes a subtle judgement, but my impression is that other third-person pronouns in English are degraded in the meaning that we are currently investigating or, at best, cannot actually be shown to have it due to interfering factors. I will start by discussing he and she and then make some remarks about they.

To begin with, then, there is evidence that he and she cannot have generalizedquantifier meanings:
A: Every boy is happy.
B: *No, he isn't!

Some examples from my survey of native speakers are relevant in confirming these judgements. There was a contrast between the following two dialogues.

(14) Consider the following dialogue:

A: Every boy is happy.

B: No, he isn't!

Can B's reply here mean 'No, it's not the case that every boy is happy'?

Consider the following dialogue:

A: Every towel has a purpose.

B: No, it doesn't!

Can B's reply here mean 'It's not the case that every towel has a purpose'?

This time, 46 respondents answered both questions, of whom 4 answered 'Not sure' for one or both questions and are not included in this analysis. Of the remaining 42, 28 answered yes to both questions, 0 answered yes to (14) and no to (15), 11 answered yes to (15) and no to (14), and 3 answered no to both. Once again, the crucial contrast is between the second and third groups: 11 answered yes to (15) and no to (14) but no-one did the converse. This is a very significant contrast, meaning that the null hypothesis (that there is no difference in acceptability between the two sentences in the relevant meanings) is extremely unlikely to be true (McNemar's $\chi^{2}=9.0909$, df $=1, p=0.002569$ ). The irrelevance of the people answering yes to both questions is underlined in this case by the fact that several respondents, in optional comments, said that they took he in (14) to be referring to some particular boy; they evidently said yes because they took the sentence, thus interpreted, to be evidence for the truth of the proposition that I was actually asking about.

The following two dialogues were designed to test she and a different syntactic configuration.

(16) Consider the following passage:

No girl came in, but he had not expected her to.

Can this mean 'No girl came in, but he had not expected any girl to come in'?

(17) Consider the following passage:

Nothing happened, but he had not expected it to.

Can this mean 'Nothing happened, but he had not expected anything to happen'? 
In all, 45 respondents answered both questions, of whom 6 answered 'Not sure' to one or both and are not included in this analysis. Of the remaining 39, 11 answered yes to both questions, 0 answered no to (17) and yes to (16), 24 answered yes to (17) and no to (16), and 4 answered no to both. Once again, this is an extremely strong contrast between the acceptability of (16) in the relevant meaning (disfavoured) and the acceptability of (17) in the relevant meaning (favoured) (McNemar's $\chi^{2}=22.042$, df $=1, p=2.668 \times 10^{-6}$ ).

It is worth recalling that Cardinaletti and Starke (1999) pointed out some structural and prosodic ways in which the pronoun it differed from he and she. These latter pronouns, but not it, for example, can be coordinated in constructions like the following:

a. He and the other one are nice.

b. *It and the other one are nice.

And he and she but not it can take part in association with focus by means of only:

a. John only saw HER.

b. *John only saw IT.

Perhaps relatedly, he and she but not it can serve as the pronoun in Voldemort phrases (Elbourne 2005, 2013). ${ }^{9}$
a. He Who Must Not Be Named
b. She who must be obeyed
c. *It which rolls fastest
d. That which rolls fastest

So the idea that it is a different kind of thing from he and she (beyond the difference in gender features) is not new; another dimension, however, is now being added to the variation.

Let us move on to they. Here the picture is slightly murkier. In informal responses (not part of my online survey), some informants have found the following example good and some have found it bad in the relevant reading:

(21) Some exciting things will happen this summer. \% They always do.

And an anonymous reviewer for this journal, who finds (21) bad, says that, by contrast, he or she finds the following examples to be fine:

(22) Some mistakes will undoubtedly creep in. They always do.

(23) A: Every human has a purpose on this earth.

B: No, they don't.

\footnotetext{
${ }^{9}$ More recent study has alerted me to the possibility that $i t$ might not have obeyed this constraint in Early Modern English: in Hobbes's Leviathan (Part I, Chapter VI, 'Good Evill'; 1651), we read, 'But whatsoever is the object of any mans Appetite or Desire; that is it, which he for his part calleth Good.' But I will leave this issue for further research.
} 
I do not know how to account for this variation between speakers. But to the extent that examples like this are acceptable, I do not think that they give good reason to think that they is a QP-anaphor.

The problem is that other analyses present themselves. In the case of (21) and (22), it seems to me that versions of these sentences in which a bare plural is substituted for they are perfectly good paraphrases:

(24) Some exciting things will happen this summer. Exciting things always happen.

Some mistakes will undoubtedly creep in. Mistakes always creep in.

So it seems as if we could account for (21) and (22) by supposing that they can have the semantics of a bare plural. And indeed Carlson (1977, p. 425) observed long ago that (26a) is synonymous with (26b):

a. Queenie is seeking unicorns and Phil is seeking them too.

b. Queenie is seeking unicorns and Phil is seeking unicorns too.

Unfortunately there is a considerable amount of disagreement about the semantics of bare plurals. But amongst the rival theories we should note that some of the most prominent do not give bare plurals the meanings of generalized quantifier phrases: Carlson (1977, p. 442) claims that bare plurals are referential and refer to kinds, where kinds are individuals; while Chierchia (1998) and Zweig (2009) maintain that they denote predicates. So (21) and (22), since they can plausibly be paraphrased as (24) and (25), are not good evidence for they being a QP-anaphor.

One could say something similar about (23). That is, one could suggest the following paraphrase:

A: Every human has a purpose on this earth.

B: No, humans don't have a purpose.

This strikes me as being possible. But another option in this case is to say that they in (23) is simply referential and refers to the individual sum of humans on this earth. Add to these the possibility that they actually means 'every human' in this example. I find it hard to choose between these options. Presumably the answer will depend on the exact meaning of B's reply in (23). Does it mean 'It is not the case that every human has a purpose', thus favouring the QP-anaphor hypothesis? Or 'Humans do not have a purpose', favouring the bare plural hypothesis? Or 'Every human does not have a purpose', favouring the referential hypothesis? (I assume that distributivity, combined with reference to the individual sum of humans on earth, will give us this last meaning.) I find it very hard to tell.

We should not leave this topic without considering the quantifier most. Imagine two people who have organized a fancy dinner with a choice of desserts. The following dialogue might take place afterwards:

A: Most people chose the apple pie.

B: No, they didn't. 
Can B's reply mean 'It is not the case that most people chose the apple pie'? I find it difficult to say. If you are tempted to answer yes, are you sure that you are not mistaking a meaning 'People didn't choose the apple pie', with bare plural semantics, for something involving 'most people...'? I suspect it will be hard to tell. For the moment, then, it is wisest to regard the hypothesis that they is a QP-anaphor as being not proven.

Before we bring this section to a close, here are a couple of final observations, returning to the behaviour of he and she. Firstly, if it were needed, the data in this section put a final nail in the coffin of the idea that telescoping is behind the phenomenon in question. Telescoping allows examples with he and she perfectly well, as we have seen in (4) and (5).

More interesting are the consequences of the latest round of data for the sceptical hypothesis floated at the end of Section 3, to the effect that there is a phonologically null quantifier phrase that can pick up a value anaphorically and bind pronouns. If there were such a thing, it would be a mystery why it could not bind he and she. The best that an advocate of this position could do would be to say that the lexical item in question came fitted with neuter and singular features; this would explain why it could only bind it. But note that the item in question is now even closer to it as I describe it than it was before: it is a neuter singular QP anaphor. Why posit an invisible item of this kind when right before our eyes, in all the requisite locations, there is already something that everyone already agrees is a neuter singular anaphor?

\section{Notes on scope}

It will not have escaped the reader that the scopal behaviour of the alleged QPanaphor it in the construction under investigation has displayed a pattern: it always seems to have low scope with respect to any overt VP-level operators in its sentence (or in its minimal clause, in embedded examples). Example (1), for instance, means 'It is not the case that every towel has a purpose'; as far as I can tell, it actually cannot mean 'Every towel is such that it does not have a purpose'. The analogous observation holds about the other examples of this construction that we have seen ((2), (3), (7), (8), (12)) and the VP-level operators in them (not and always). ${ }^{10}$

This is odd behaviour, to say the least. Compulsory low scope for a nominal element suggests some kind of polarity licensing phenomenon, of course, but as far as I can see it is not the case that QP-anaphor it has to be licensed by some operator, since it can occur without any operators in the same sentence:

In light of the vast literature on linguistic relativity hypotheses, one would expect that a good deal of careful experimental work had been done on the topic. It has.

The only other parallel that springs to mind is Carlson's (1977) demonstration that bare plurals have to take narrow scope with regard to scope-bearing elements in their

\footnotetext{
${ }^{10}$ Example (8) does not contain any VP-level operator in the clause where it occurs, so this example passes by default, as it were. The other examples seem straightforward to me. For an explicit treatment of always as a VP-level operator, see Elbourne 2016.
} 
sentences. The following pair (Carlson 1977, p. 420) shows this property with respect to negation and thus forms a close parallel with some of the data in the current article:

\section{a. A goat didn't run across my lawn.}

b. Goats didn't run across my lawn.

Example (30a) has a reading in which the subject scopes over negation; but this is not the case in (30b), where the subject has to scope under negation (assuming, for the moment, that we give it existential force). Carlson explained this by saying that bare plurals were not quantifier phrases but instead referred to kinds; since they were basically referential, they could not be expected to take wide scope with respect to negation (and other operators) in the way that quantifier phrases would. As remarked earlier, other theorists, such as Chierchia (1998), have proposed that bare plurals refer to properties, again making them be of a type other than that of generalized quantifiers. But this kind of move cannot plausibly be of any use to us in the present case, since the data that we have surveyed point to the conclusion that the occurrences of it under analysis do precisely have the semantics of generalized quantifiers.

I find myself unable to offer any deep explanation of this behaviour. But that does not mean that we cannot do the next-best thing and provide a sketch of a way of dealing with it in an explicit grammar. One way of modelling the behaviour of it explored in this article would be to say that this pronoun, perhaps in addition to other meanings, is interpreted as a free variable of generalized quantifier type. But it would be hard to limit a self-standing lexical item of that kind to appearing only in the limited configurations in which we find the current meaning for $i$, which are discussed in this section and the next. A more fruitful approach, in my opinion, would be to posit a new kind of ellipsis process or, more precisely, a pronominalization process that applies to generalized quantifiers. I will be guided by Minimalist syntactic theory and place the origin of this idiosyncrasy in the lexicon, just as Merchant $(2001,2013)$ does with his E feature that triggers ellipsis. In fact it is worth comparing the two posited features. In his more recent presentation, Merchant $(2013,85,88-90)$ restricts the placement of the E feature to C $[+$ wh, $+\mathrm{Q}]$ (for sluicing) and a Kratzerian Voice head (Kratzer 1996) (for VP-ellipsis, actually vP-ellipsis according to Merchant); he says that the presence of the feature will require syntactic identity of the phrase taken as complement by the feature's host with a phrase in the linguistic environment; and he says that the feature will trigger non-pronunciation of the phrase taken as complement by the feature's host. Along rather similar lines, I propose the existence of a pronominalization feature P: subsequent to revision, it will be restricted to appearing on the heads of neuter singular quantifier phrases that bear features indicating that they will reconstruct; ${ }^{11}$ the presence of the feature on such a phrase will require syntactic identity of that phrase with a phrase in the linguistic environment; and the feature will trigger a reduced pronunciation ('it') of the phrase on which it appears. It can be seen that the two features are rather similar, with $\mathrm{P}$, if anything, being slightly less complicated than $\mathrm{E}$. The only matter that might give one pause is the mention of features that indicate that a quantifier phrase will reconstruct. But this is a standard feature of Minimalist syntax, in which movement is triggered by a Probe-Goal

${ }^{11}$ I assume that only subjects can reconstruct in the relevant way; if this is not the case we might have to add a restriction to appearing on subjects. 
relationship, with both Probe and Goal status being realized by features (Chomsky 2001); a version of this idea dealing with reconstruction in particular is spelled out in Elbourne 2016.

We might suspect that there is a deeper story to tell about the reason for this obligatory low scope, but we can still learn something useful from it. In fact we can learn something from the existence of any examples in which the quantifier in this construction scopes below negation. I will adopt the standard assumption that not occupies a projection above the level of the VP, below the canonical subject position (Pollock 1989). The hypothesis according to which the quantificational force in these examples is contributed by it can say, of course, that this pronoun in subject position scopes below not by whatever mechanism is used by normal subject quantifier phrases when they scope below not. Perhaps reconstruction to a VP- or vP-internal subject position is involved. But what can be said by the advocate of the rival hypothesis, according to which there is a phonologically null QP-anaphor with neuter singular features? Such a theorist, of course, will say that the null anaphor can be positioned below not and above the VP; so all seems well. But what happens to the pronoun it in such a scenario? Recall that according to this rival hypothesis, it is bound by the null anaphor. Now if it is left in the canonical subject position, it will not be bound by the null anaphor in the case of the null anaphor scoping below not, since it will not be in its scope. So in order to maintain the desired interpretation, a theorist of this stripe will have to say that it reconstructs to a position below the position of the null anaphor, which is in turn below negation. Now there is nothing impossible in this, of course; and indeed, as just discussed, I have to say that it reconstructs in these examples too. But notice what the overall position of the rival theorist is now: not only is there a phonologically null QP-anaphor with neuter singular features, which is posited in spite of the fact that it, an overt anaphor with neuter singular features, exists in all the needed places; it is also the case that the overt pronoun follows the null anaphor around. This, I submit, is taking redundancy too far. I will henceforth assume that it has been shown to be a QP-anaphor.

\section{Notes on syntax}

Another obvious characteristic of the examples of QP-anaphor it that we have examined is that they have all contained VP-ellipsis. If we replace the elided VP in (1) (repeated here as (31)) with a full VP of equivalent meaning, the example is notably worse on the relevant reading:

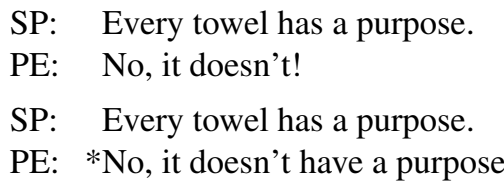

The effect is also felt with the other examples we have seen.

Since this is unexpected, to say the least, I checked reactions to (31) and (32) in my online survey: 
Consider the following dialogue:

A: Every towel has a purpose.

B: No, it doesn't have a purpose!

Can B's reply here mean 'No, it's not the case that every towel has a purpose'?

(34) Consider the following dialogue:

A: Every towel has a purpose.

B: No, it doesn't!

Can B's reply here mean 'No, it's not the case that every towel has a purpose'?

In all, 46 respondents answered both questions, of whom 8 answered 'Not sure' to one or both and are not included in this analysis. ${ }^{12}$ Of the remaining 38, 17 answered yes to both questions, 0 answered no to (34) and yes to (33), 17 answered yes to (34) and no to (33), and 4 answered no to both. This indicates an extremely strong contrast between the acceptability of (33) in the relevant meaning (disfavoured) and the acceptability of (34) in the relevant meaning (favoured) (McNemar's $\chi^{2}=15.059$, df $=1, p=0.0001042$ ).

As far as I can tell, no other kind of ellipsis licenses the reading in question. Here is a pair that might lead one to suspect that the phenomenon under investigation does not arise with gapping:

Every towel has a purpose and every towel an owner.

*Every towel has a purpose and it an owner.

An anonymous reviewer for this journal points out that it is also ungrammatical to say (37):

*A $\operatorname{dog}_{i}$ has a bone and it $_{i}$ a biscuit.

This is not a case of QP-anaphor it, of course, but just ordinary discourse anaphora; but it is bad anyway. So there seems to be a more general constraint in operation that makes it ungrammatical in the relevant configuration, meaning that (36) might be ruled out just because of that. But of course this does not make (36) alright or indicate that other attempted examples of gapping with QP-anaphor it will succeed; quite the contrary. We can conclude, then, that QP-anaphor it probably does not work with gapping but we do not know why. Moving on to a different kind of ellipsis, it seems that NP-deletion within the relevant VP does not help things along:

Every towel has a purpose.

a. No, it doesn't.

b. *No, it doesn't have one.

\footnotetext{
${ }^{12}$ It is perhaps worth noting that all eight of those who answered 'Not sure' to these questions did so in answer to the deviant (33), which might be taken to be evidence of anomaly in itself; two of these eight (and no others) also answered 'Not sure' to (34).
} 
I find it hard even to construct plausible examples of the phenomenon that involve other kinds of ellipsis (that is, examples where there is a relevant good sentence to include in a minimal pair).

Once again, this is extremely unusual behaviour. But there is a parallel. Tag questions involve compulsory VP-ellipsis (Klima 1964; Huddleston 1970; Culicover 1992):

a. John won't be there, will he?

b. *John won't be there, will he be there?

And, as we would expect if there is a link between the two phenomena, examples of $\mathrm{QP}$-anaphor it can be found in tag questions. Here is another spontaneous utterance of mine from long ago:

LP: Shall we get something to eat?

PE: Nowhere'll be open now, will it?

I follow Huddleston (1970), Culicover (1992), and Reese and Asher (2019) (as opposed to Klima (1964)) in maintaining that the basic syntax of a main clause followed by a tag question is paratactic and involves two full sentences juxtaposed. This makes it unlikely that it in (40) is simply bound by nowhere; and it certainly is not referential. The likelihood of binding being involved is decreased still further by the following data:
a. Nothing will do that, will it?
b. *No man will do that, will he?
c. *No woman will do that, will she?
d. (Talking about a group of women...) *No-one will do that, will she?

If nowhere in (40) could bind into the tag question and ensure that the utterance was not rendered unacceptable due to a lack of interpretation for it, so could no man, no woman, and no-one in $(41 \mathrm{~b}-\mathrm{d})$; but these latter examples are unacceptable. We should also note, of course, that the inability of he and she to take part in the construction in (41) is exactly parallel to the previously noted inability of he and she to be QP-anaphors; see Section 4. ${ }^{13}$ I conclude that (40) is another example of it acting as a QP-anaphor. Following Huddleston (1970) and Reese and Asher (2019), who convincingly argue that tag questions are genuine questions, I propose that the tag in (40) means '... will anywhere be open?'; this recalls the behaviour of QP-anaphor it that we saw in (9), where it was also anaphoric to a negative indefinite and seemed to contribute something with the semantics of an NPI.

It is a reasonable hypothesis, then, that the compulsory VP-ellipsis we have noted with QP-anaphor it is connected to, and may even be the same basic phenomenon as, the compulsory VP-ellipsis in tag questions. This is the good news. The bad news is that the analysis of compulsory VP-ellipsis in tag questions is not in a very highly

\footnotetext{
${ }^{13}$ We should also inquire about the behaviour of they in the relevant tag-question construction, of course. But I find it hard to know exactly what is going on here. In examples like No people will do that, will they?, which seems better than $(41 \mathrm{~b}-\mathrm{d})$, I find it hard to rule out a referential reading, with they referring to the sum of the people quantified over. I leave this issue for future research.
} 
developed state; and it is unclear to what extent this identification brings any further insight into the case of compulsory VP-ellipsis with QP-anaphor it. To begin with, we can dismiss the analysis of Klima (1964), since he takes main clause plus tag question to consist of only one clause, rearranged by a transformation. Most data examined in this article, however, quite clearly consist of sequences of two sentences. And besides, Huddleston (1970) presented independent arguments against Klima that are compelling.

The main alternative, which originates in Culicover 1992 and is endorsed by Reese and Asher (2019), is to say that tag questions are independent sentences, separate from the main clause, but that they belong to a special category of pronominal IPs. A pronominal IP, according to Culicover (1992, p. 202), has the following characteristics (where reference is made back to the main clause in a tag question construction): 'The subject must be a pronominal copy of the main subject, the auxiliary must be a copy of the main auxiliary, and the VP must be the elliptical counterpart of the main VP.' It is also possible for a pronominal IP to incorporate a negation not found in the main clause, of course.

As applied to the data examined in this article, we would have to add that quantificational adverbs can also be added to the elements mentioned in the initial definition, given the examples with always in Section 3. This might not be a big deviation from Culicover's original conception. There is one way, however, in which the data examined in this article contradict Culicover's instructions for forming pronominal IPs. Consider (7), repeated here in simplified form as (42):

Something's sure to happen. It always does.

We see here that the auxiliary in the second sentence need not be a copy of the one in the first. If we are to pursue the parallel, then, it seems that we will have to posit a superordinate category of which Culicover's pronominal IPs and examples like the second sentence in (42) will be sub-categories. Call the superordinate category the category of anaphoric sentences: an anaphoric sentence is a monoclausal sentence in which the subject has to be an anaphoric pronoun and the VP has to be elided, both these anaphoric devices being resolved with respect to the same antecedent sentence. Then one subcategory of anaphoric sentences would be pronominal IPs as defined by Culicover: tag questions would be anaphoric sentences that have to have the same auxiliary as the antecedent sentence and can be supplemented by negation. The examples examined in the current article, on the other hand, would be anaphoric sentences that can be supplemented with negation or a quantificational adverb but have no restrictions as to the auxiliary.

I suspect that there may very well be something to this idea; I think it is worthy of further development. But I must confess that, as it stands, it is lacking as an explanation of why QP-anaphor it is accompanied by compulsory VP-ellipsis. If there are such things as anaphoric sentences, it makes perfect sense that QP-anaphor it should be employed in them. But why should it not appear in other environments too? It is not as if other pronouns or VP-ellipsis are restricted to appearing in anaphoric sentences. At the moment I cannot think of any deep explanation for this.

We can, however, pursue our feature-based mechanism for incorporating these facts in an explicit grammar. For this purpose, I will abandon the speculations just 
made about anaphoric sentences and just work with the notion of compulsory VPellipsis. In Section 5, I proposed a feature $\mathrm{P}$ that could be placed on quantifier phrases, with the following restrictions and effects: it is restricted to appearing on the heads of neuter singular quantifier phrases that bear features indicating that they will reconstruct; the presence of the feature on such a phrase will require syntactic identity of that phrase with a phrase in the linguistic environment; and the feature will trigger a reduced pronunciation ('it') of the phrase on which it appears. In order to accommodate the data considered in the current section we just need to amend the first clause above to say that the feature is restricted to appearing in clauses with VP-ellipsis on the heads of neuter singular quantifier phrases that bear features indicating that they will reconstruct. Following Merchant (2013) in his analysis of VP- (or vP-) ellipsis, we might imagine the extra condition being realized as a requirement that the quantifier phrases in question be c-commanded at some point in the derivation by an $\mathrm{E}$ feature on Voice (i.e. when they are merged in vP). I will not attempt any further precision, however, since the details here will naturally depend on the exact theory of features (and VP-ellipsis) that any given theorist wishes to adopt. We should note, finally, that placement of this feature on quantifier phrases of this kind will be optional (again, assuming that the notion of anaphoric sentence does not play a role here): we do not need to put the feature on these quantifier phrases, and if we do not they will be spelled out as normal, producing sequences like the following:

Something's sure to happen. Something always does.

So the parallel between this phenomenon and VP-ellipsis, which of course is also optional except in the constrained circumstances discussed here, is again very close.

Relatedly, it is worth remarking that the syntactic identity condition that obtains with respect to QP-anaphor it displays some of the same quirks that bedevil the syntactic identity condition that governs VP-ellipsis (again assuming that a condition of this kind is the best analysis here and not something like Merchant's (2001) e-GIVENness). Those familiar with the ellipsis literature will recall that NPIs seem to be good antecedents for standard indefinites and vice versa (Sag 1976, pp. 157f):

a. John doesn't see anyone, but Bill does.

b. John sees someone, but Bill doesn't.

The point is, of course, that attempting to resolve the ellipsis in (44a) with see anyone is ungrammatical, while using see someone is just fine; similarly, but in reverse, with (44b). Those familiar with classic English detective fiction may already have noticed that exactly the same phenomenon arises with regard to QP-anaphor it:

'No, I don't think there's anything to show that everyone in the household is now in danger, I really don't. I mean it's not as though any further attempt had been made...'

'You can bet your sweet life it hasn't!'

(Margery Allingham, More Work for the Undertaker, Chapter 4)

The pronoun it in the last sentence of this example seems to mean 'a further attempt'. Trying to resolve the pronominalization using the NPI antecedent results in ungrammaticality, whereas an attempt to resolve it with a further attempt does not: 
a. *You can bet your sweet life any further attempt hasn't been made!

b. You can bet your sweet life a further attempt hasn't been made!

This is, of course, precisely parallel to the facts about VP-ellipsis exemplified in (44); presumably the same range of analytical options will present themselves. The natural hypothesis is that the syntactic identity relation that plays a role in the grammar of QP-anaphor it is the same as the one that is involved in VP-ellipsis. I will not attempt to uncover more details of the relevant syntactic identity relation in this article, however, but will leave this task for future research. There are a lot more classic detective novels out there.

\section{Conclusion}

The English pronoun it, in the conditions just formulated, can have the meaning of a salient quantifier phrase, having apparently picked up this meaning in an anaphoric process. A question arises as to whether more general theories of pronoun interpretation, of the kind surveyed in the Introduction to this article, should be changed to accommodate this fact. I think it is too early to tell and that the answer will depend to a large extent on whether other languages display similar phenomena. If the English facts are part of a crosslinguistic pattern of pronoun usage, then this would suggest very strongly that there is something about pronouns in general that leads them to behave in this manner, and changes might have to made in our general theories to enable them to accommodate the relevant facts in a unified way. But establishing such a pattern, if it is there to be established, lies beyond the scope of the current article.

It is also worth noting that the facts surveyed in this article have arguably brought support to decompositional theories of negative indefinites and have provided a second kind of environment in which the syntactic identity relation involved in VPellipsis is seemingly in play. It is to be hoped that these observations will be useful for scholars involved in the analysis of those phenomena.

Acknowledgements I dedicate this article to Irene Heim, with thanks for all the inspiration she has provided me with over the years. I originally started working on it several years ago, intending that it would be a contribution to the Festschrift that was produced to mark her 60th birthday (Crnič and Sauerland 2014); but I was unable to complete it in time for inclusion in that volume, a circumstance that has been a source of great regret to me ever since.

For valuable comments on drafts of the manuscript, I am grateful to Christine Bartels, James Kirkpatrick, and two anonymous reviewers for this journal.

Open Access This article is licensed under a Creative Commons Attribution 4.0 International License, which permits use, sharing, adaptation, distribution and reproduction in any medium or format, as long as you give appropriate credit to the original author(s) and the source, provide a link to the Creative Commons licence, and indicate if changes were made. The images or other third party material in this article are included in the article's Creative Commons licence, unless indicated otherwise in a credit line to the material. If material is not included in the article's Creative Commons licence and your intended use is not permitted by statutory regulation or exceeds the permitted use, you will need to obtain permission directly from the copyright holder. To view a copy of this licence, visit http://creativecommons.org/licenses/by/ 4.0\%. 


\section{References}

Anderssen, J. 2011. Quantification, misc. PhD thesis, University of Massachusetts at Amherst.

Barker, C., and C. Shan. 2008. Donkey anaphora is in-scope binding. Semantics \& Pragmatics 1: 1-40.

Belvadi, A. 1989. Quantified NPs and pronouns. Unpublished manuscript, University of Rochester.

Cardinaletti, A., and M. Starke. 1999. The typology of structural deficiency: A case study of the three classes of pronouns. In Clitics in the languages of Europe, ed. H. van Riemsdijk, 145-234. Berlin: Mouton de Gruyter.

Carlson, G. 1977. A unified analysis of the English bare plural. Linguistics and Philosophy 1: 413-458.

Chierchia, G. 1998. Reference to kinds across language. Natural Language Semantics 6(4): 339-405.

Chomsky, N. 2001. Minimalist inquiries: The framework. In Step by step-Essays in minimalist syntax in honor of Howard Lasknik, eds. R. Martin, D. Michaels, and J. Uriagereka, 89-155. Cambridge, MA: MIT Press.

Cooper, R. 1979. The interpretation of pronouns. In Syntax and semantics 10: Selections from the Third Gröningen Round Table, eds. F. Heny and H. Schnelle, 61-92. New York: Academic Press.

Crnič, L. and U. Sauerland, eds. 2014. The art and craft of semantics: A Festschrift for Irene Heim. Cambridge, MA: MIT Working Papers in Linguistics.

Culicover, P. 1992. English tag questions in Universal Grammar. Lingua 88: 193-226.

Curry, H., and R. Feys. 1958. Combinatory logic. Amsterdam: North Holland.

Davies, M. 1981. Meaning, quantification, necessity. London: Routledge and Kegan Paul.

Elbourne, P. 2001. E-type anaphora as NP-deletion. Natural Language Semantics 9(3): 241-288.

Elbourne, P. 2005. Situations and individuals. Cambridge, MA: MIT Press.

Elbourne, P. 2008. Demonstratives as individual concepts. Linguistics and Philosophy 31: 409-466.

Elbourne, P. 2011. Meaning: A slim guide to semantics. Oxford: Oxford University Press.

Elbourne, P. 2013. Definite descriptions. Oxford: Oxford University Press.

Elbourne, P. 2016. Incomplete descriptions and indistinguishable participants. Natural Language Semantics 24(1): 1-43.

Evans, G. 1977. Pronouns, quantifiers and relative clauses (I). Canadian Journal of Philosophy 7: 467-536.

Evans, G. 1980. Pronouns. Linguistic Inquiry 11: 337-362.

von Fintel, K. 1998. Quantifiers and 'if'-clauses. The Philosophical Quarterly 48(191): 209-214.

Fodor, J. D., and I. Sag. 1982. Referential and quantificational indefinites. Linguistics and Philosophy 5: 355-398.

Frege, G. 1903. Grundgesetze der Arithmetik. Jena: Hermann Pohle.

Geach, P. 1962. Reference and generality: An examination of some medieval and modern theories. Ithaca, N.Y.: Cornell University Press.

Groenendijk, J., and M. Stokhof. 1990. Dynamic Montague Grammar. In Papers from the second symposium on logic and language, eds. L. Kálmán and L. Pólos, 3-48. Budapest: Akadémiai Kiadó.

Groenendijk, J., and M. Stokhof. 1991. Dynamic predicate logic. Linguistics and Philosophy 14: 39-100.

Heim, I. 1982. The semantics of definite and indefinite noun phrases, PhD thesis, University of Massachusetts, Amherst.

Heim, I. 1990. E-type pronouns and donkey anaphora. Linguistics and Philosophy 13: 137-177.

Huddleston, R. 1970. Two approaches to the analysis of tags. Journal of Linguistics 6(2): 215-222.

Jacobs, J. 1980. Lexical decomposition in Montague-grammar. Theoretical Linguistics 7: 121-136.

Jacobson, P. 1999. Towards a variable-free semantics. Linguistics and Philosophy 22: 117-184.

Jacobson, P. 2000. Paycheck pronouns, Bach-Peters sentences, and variable-free semantics. Natural Language Semantics 8: 77-155.

Kamp, H. 1981. A theory of truth and semantic representation. In Formal methods in the study of languages, eds. J. Groenendijk, T. Janssen, and M. Stokhof, 277-322. Amsterdam, Mathematical Centre.

Keshet, E. 2008. Telescoping and scope economy. In Proceedings of the 26th West Coast conference on formal linguistics, eds. C. Chang and H. Haynie, 324-331. Somerville, MA: Cascadilla.

Klima, E. 1964. Negation in English. In The structure of language: Readings in the philosophy of language, eds. J. Fodor and J. Katz, 246-323. Englewood Cliffs, NJ: Prentice Hall.

Kratzer, A. 1996. Severing the internal argument from its verb. In Phrase structure and the lexicon, eds. J. Rooryck and L. Zaring, 109-137. Dordrecht: Kluwer.

Link, G. 1983. The logical analysis of plurals and mass terms: A lattice-theoretical approach. In Meaning, use and interpretation of language, eds. R. Bäuerle, C. Schwarze, and A. von Stechow, 302-323. Berlin: de Gruyter. 
Meier, C. 2003. The meaning of too, enough, and so... that. Natural Language Semantics 11: 69-107.

Merchant, J. 2001. The syntax of silence: Sluicing, islands, and the theory of ellipsis. Oxford: Oxford University Press.

Merchant, J. 2013. Voice and ellipsis. Linguistic Inquiry 44(1): 77-108.

Montague, R. 1973. The proper treatment of quantification in ordinary English. In Approaches to natural language: Proceedings of the 1970 Stanford workshop on grammar and semantics, eds. J. Hintikka, J. Moravcsik, and P. Suppes, 221-242. Dordrecht: Reidel.

Myers, J. 2009. The design and analysis of small-scale syntactic judgment experiments. Lingua 119: $425-444$.

Neale, S. 1990. Descriptions. Cambridge, MA: MIT Press.

Neale, S. 2006. Pronouns and anaphora. In The Blackwell guide to the philosophy of language, eds. M. Devitt and R. Hanley, 335-373. Oxford: Blackwell.

Nunberg, G. 1993. Indexicality and deixis. Linguistics and Philosophy 16: 1-43.

Partee, B. 1986. Noun phrase interpretation and type-shifting principles. In Studies in discourse representation theory and the theory of generalized quantifiers, eds. J. Groenendijk, D. de Jongh, and M. Stokhof, 115-153. Dordrecht: Foris.

Partee, B. 1996. The development of formal semantics in linguistic theory. In The handbook of contemporary semantic theory, ed. S. Lappin, 11-38. Oxford: Blackwell.

Poesio, M., and A. Zucchi. 1992. On telescoping. In Proceedings of SALT 2, eds. C. Barker and D. Dowty, 347-366. Columbus, OH: The Ohio State University.

Pollock, J.-Y. 1989. Verb movement, universal grammar, and the structure of IP. Linguistic Inquiry 20(3): 365-424

Quine, W.v.O. 1960. Variables explained away. Proceedings of the American Philosophical Society 104: 343-347.

Reese, B., and N. Asher. 2019. Prosody and the interpretation of tag questions. In Proceedings of Sinn und Bedeutung 11, eds. L. McNally and E. Puig-Waldmüller, 448-462. Barcelona: Universitat Pompeu Fabra.

Roberts, C. 1987. Modal subordination, anaphora, and distributivity, PhD thesis, University of Massachusetts at Amherst.

Roberts, C. 1989. Modal subordination and pronominal anaphora in discourse. Linguistics and Philosophy 12: 683-721.

Rullmann, H. 1995. Geen eenheid. Tabu 25(4): 194-197.

Sag, I. 1976. Deletion and logical form, PhD thesis, MIT.

Swoyer, C. 2010. Relativism. In The Stanford encyclopedia of philosophy, ed. E.N. Zalta. Winter. 2010. Metaphysics Research Lab, Stanford University.

Szabolcsi, A. 1989. Bound variables in syntax: Are there any? In Semantics and contextual expression, eds. J. van Benthem and P. van Emde Boas, 295-318. Dordrecht: Foris.

van Eijck, J., and H. Kamp. 1997. Representing discourse in context. In Handbook of logic and language, eds. J. van Benthem and A. ter Meulen, 179-237. Amsterdam/Cambridge, MA: Elsevier/MIT Press.

Zeijlstra, H. 2011. On the syntactically complex status of negative indefinites. Journal of Comparative Germanic Linguistics 14: 111-138.

Zweig, E. 2009. Number-neutral bare plurals and the multiplicity implicature. Linguistics and Philosophy 32(4): 353-407.

Publisher's Note Springer Nature remains neutral with regard to jurisdictional claims in published maps and institutional affiliations. 